\title{
BMJ Open Sugar-sweetened beverage (SSB) consumption, correlates and interventions among Australian Aboriginal and Torres Strait Islander communities: a scoping review
}

To cite: Wright KM, Dono J, Brownbill AL, et al. Sugarsweetened beverage (SSB) consumption, correlates and interventions among Australian Aboriginal and Torres Strait Islander communities: a scoping review. BMJ Open 2019;9:e023630. doi:10.1136/ bmjopen-2018-023630

- Prepublication history and additional material for this paper are available online. To view these files, please visit the journal online (http://dx.doi. org/10.1136/bmjopen-2018023630).

Received 16 April 2018

Revised 18 November 2018 Accepted 20 November 2018

Check for updates

(C) Author(s) (or their employer(s)) 2019. Re-use permitted under CC BY-NC. No commercial re-use. See rights and permissions. Published by BMJ.

For numbered affiliations see end of article.

Correspondence to Kathleen M Wright;

kathleen.wright@sahmri.com

\section{ABSTRACT}

Objectives Sugar-sweetened beverage (SSB) consumption in Australian Aboriginal and Torres Strait Islander people is reported to be disproportionally high compared with the general Australian population. This review aimed to scope the literature documenting SSB consumption and interventions to reduce SSB consumption among Australian Aboriginal and Torres Strait Islander people. Findings will inform strategies to address SSB consumption in Aboriginal and Torres Strait Islander communities.

Methods PubMed, SCOPUS, CINAHL, Informit, Joanna Briggs Institute EBP, Mura databases and grey literature were searched for articles published between January 1980 and June 2018. Studies were included if providing data specific to an Australian Aboriginal and/or Torres Strait Islander population's SSB consumption or an intervention that focused on reducing SSB consumption in this population.

Design Systematic scoping review.

Results 59 articles were included (1846 screened). While reported SSB consumption was high, there were agerelated and community-related differences observed in some studies. Most studies were conducted in remote or rural settings. Implementation of nutrition interventions that included an SSB component has built progressively in remote communities since the 1980s with a growing focus on community-driven, culturally sensitive approaches. More recent studies have focused exclusively on SSB consumption. Key SSB-related intervention elements included incentivising healthier options; reducing availability of less-healthy options; nutrition education; multifaceted or policy implementation (store nutrition or government policy).

Conclusions There was a relatively large number of studies reporting data on SSB consumption and/or sales, predominantly from remote and rural settings. During analysis it was subjectively clear that the more impactful studies were those which were community driven or involved extensive community consultation and collaboration. Extracting additional SSB-specific consumption data from an existing nationally
Strengths and limitations of this study

- This review provides a detailed overview of existing data regarding sugar-sweetened beverage (SSB) consumption in the Australian Aboriginal and Torres Strait Islander population, and results are likely to be of interest to researchers, communities and policymakers.

- A variety of measurement methods of SSB consumption were present within included studies, which limited comparisons across population groups.

- A formal appraisal of quality was not included; however, it was clear that there was variability in quality between included studies.

representative survey of Aboriginal and Torres Strait Islander people could provide detailed information for demographic subgroups and benchmarks for future interventions. It is recommended that a consistent, culturally appropriate, set of consumption measures be developed.

\section{INTRODUCTION}

Global incidence of non-communicable chronic disease is increasing, which is evident within both the total Australian and the Indigenous Australian (Aboriginal and Torres Strait Islander) population. ${ }^{12}$ Aboriginal and Torres Strait Islander people experience unacceptable health inequalities compared with other Australians, with a range of social and cultural factors stemming from colonisation identified as contributors to poor health. ${ }^{34}$ These include racism, loss of language and connection to the land, and spiritual disconnectedness. Deaths from chronic disease have been identified by Aboriginal and Torres Strait Islander communities as a specific health concern, with type 
2 diabetes in particular highlighted as a priority area for future research. ${ }^{5}{ }^{6}$ Of the non-communicable chronic diseases, type 2 diabetes is increasing the fastest. ${ }^{7}$ Prevalence of type 2 diabetes is high among Aboriginal and Torres Strait Islander peoples, with national prevalence of $11.1 \%$, and an additional $4.7 \%$ at high risk. ${ }^{8}$ Prevalence of overweight and obesity is also high, at $66.0 \%$ for Aboriginal and Torres Strait Islander people aged 15 years or older, and $30.4 \%$ for children aged 2-14 years. ${ }^{9}$ Furthermore, Aboriginal and Torres Strait Islander people who are obese have nearly five times the prevalence of type 2 diabetes (19\%) compared with those with normal or low bodyweight ( $4 \%$ type 2 diabetes). ${ }^{5}$

Multiple factors contribute to non-communicable chronic disease but sugar-sweetened beverages (SSBs) have been singled out for a number of reasons including: (1) they are heavily consumed despite providing 'empty' (micronutrient deplete) kilojoules; (2) the additional energy acquired from SSB consumption is generally not fully compensated for by a reduction in energy from other sources, which is one pathway for weight gain ${ }^{10}$; and (3) SSB consumption has also been causally associated with type 2 diabetes, dental caries and metabolic disease, ${ }^{11}{ }^{12}$ all of which have high prevalence in Aboriginal and Torres Strait Islander communities. ${ }^{2}$ Limiting 'free sugars' in the diet, and in particular from sources such as SSBs, has been identified as a strategy to help reduce the burden of these chronic diseases. ${ }^{13}$ In Australia, SSB consumption in the general population is high, contributing an estimated $9.7 \%$ of total sugar intake at a population level. ${ }^{14}$ Furthermore, Aboriginal and Torres Strait Islander people are more likely to consume SSBs compared with other Australians. ${ }^{15}$ For these reasons, high SSB consumption is emerging as a national health issue in Australia and is a key concern for Aboriginal and Torres Strait Islander people. $^{1617}$

Successful Australian public health measures, such as those developed for tobacco control, have shown the importance of understanding the unique needs of populations experiencing health inequity. ${ }^{18}$ Without this knowledge, health interventions may fail to effectively address the most important health behaviours and social contexts, and/or may fail to engage the local community. In terms of health-based strengths and challenges, Aboriginal and Torres Strait Islander communities within Australia are likely to share both similarities and differences with each other and the broader Australian population (eg, language and cultural practices), and these factors are likely to influence both the appropriateness of, and the outcomes of health interventions. ${ }^{19}$ Relative to the wider Australian population, many (but not all) Aboriginal and Torres Strait Islander people face challenges including living in relative socioeconomic disadvantage, higher rates of unemployment and lower rates of education attainment, and these challenges are accompanied by higher rates of behavioural and environmental health risk factors such as limited availability of affordable food. ${ }^{2}$ Despite these challenges, many Aboriginal and Torres
Strait Islander people acknowledge the resilience of individuals and communities, and the importance of taking a strengths-based approach to addressing their priorities when planning health research or interventions. ${ }^{6}$

To inform strategy and policy development to address SSB consumption as a risk factor for the development of type 2 diabetes and other chronic disease in Aboriginal and Torres Strait Islander communities, a systematic scoping review was undertaken. The review aimed to identify the scope and nature of the literature that documented SSB consumption, and interventions to reduce SSB consumption among Australian Aboriginal and Torres Strait Islander people. While it was not assumed that results of interventions or consumption data would be directly generalisable across different subpopulations or communities, scoping the available literature provides an opportunity to share knowledge between communities, researchers and policymakers, and identify potential areas for future research and action. The review was designed to address the following questions:

Q1. Which demographic subgroups within the Aboriginal and Torres Strait Islander population are consuming the most SSBs and does this differ across communities?

Q2. What are the social and environmental conditions that influence SSB consumption in Aboriginal and Torres Strait Islander communities?

Q3. What interventions that aim to reduce SSB consumption in Aboriginal and Torres Strait Islander communities have been implemented and evaluated?

Q4. What interventions that aim to reduce SSB consumption in the broader Australian population have considered implementation or evaluation within Aboriginal and Torres Strait Islander communities? (Note: The wording to question 4 has been slightly modified since the publication of the protocol paper to improve its precision in relation to the aims of the study. The initial data extraction and mapping revealed that the existing search terms could not address question 4 in its original form. Conducting a new literature search using a broader set of search terms (eg, scoping for interventions applied to the general Australian population) was deemed tangential to the aim of this review which was to focus specifically on Aboriginal and Torres Strait Islander people within the broader Australian population. The modified version of question 4 could be addressed using the existing search terms.)

\section{METHODS}

The refined scoping review framework was selected ${ }^{2021}$ and a protocol was published. ${ }^{17}$ PubMed, SCOPUS, CINAHL, Informit (including Informit: Indigenous Peoples), Joanna Briggs Institute EBP Database and Mura databases were searched for records published between January 1980 and June 2018. SSBs were defined as waterbased drinks with added sugar and included soft drinks and cordials, fruit drinks, vitamin waters, energy and/or sports drinks. ${ }^{22}$ Keywords and index terms were variations 
on the terms SSBs (including specific beverage types), Aboriginal, Australian Indigenous, interventions and strategies. ${ }^{17}$ Other sources included reference lists of relevant articles, grey literature searches, conference proceedings and personal networks. Records were exported to EndNote. ${ }^{23}$ Duplicates were removed, titles and abstracts scanned for relevance, and records which clearly did not meet the inclusion criteria were excluded. The remaining full-text articles were assessed for eligibility, and relevant data extracted into tables for analysis and mapping. One author conducted all aspects of the review process. Where there was uncertainty about inclusion of an article, it was discussed within the research team and a consensus reached. Studies were not appraised for quality: the primary purpose was to extract and map available data in line with systematic scoping review methods. ${ }^{20}{ }^{21}$

Articles were included if they contained data specific to an Aboriginal and/or Torres Strait Islander population's SSB consumption, or an intervention that had a specific focus on reducing SSB consumption in this population. We included existing primary research studies (qualitative or quantitative methods), systematic and meta-analytic reviews, meta-syntheses and grey literature. Articles were excluded if published in a language other than English or if they did not contain data specific to SSBs and Australian Aboriginal and Torres Strait Islander populations. Intervention studies were excluded if they did not include at least one specific component that aimed to reduce SSB consumption or did not have a specific measure of a construct related to SSB consumption. Measures of SSB consumption varied across studies, and sugar-sweetened and non-caloric (ie, artificially sweetened or diet) drinks were not always differentiated. Therefore, it was decided to extract data for non-caloric drinks if they were measured alongside SSBs, to provide a comprehensive understanding of what was measured and reported in each study.

As detailed in the protocol, ${ }^{17}$ this research was conducted in accordance with the South Australian Aboriginal Health Research Accord's nine principles by which Aboriginal and Torres Strait Islander research should be conducted, and our research advisory group included members from the Wardliparingga Aboriginal Research Unit.

\section{Patient and public involvement}

There was no patient or public involvement in the conduct of this study.

\section{RESULTS}

The results of the search strategy are displayed in figure 1. A total of 59 articles were included in the review. For analysis, the articles were grouped into four tables which contain the full details of each study included in the review. These are provided as online supplementary

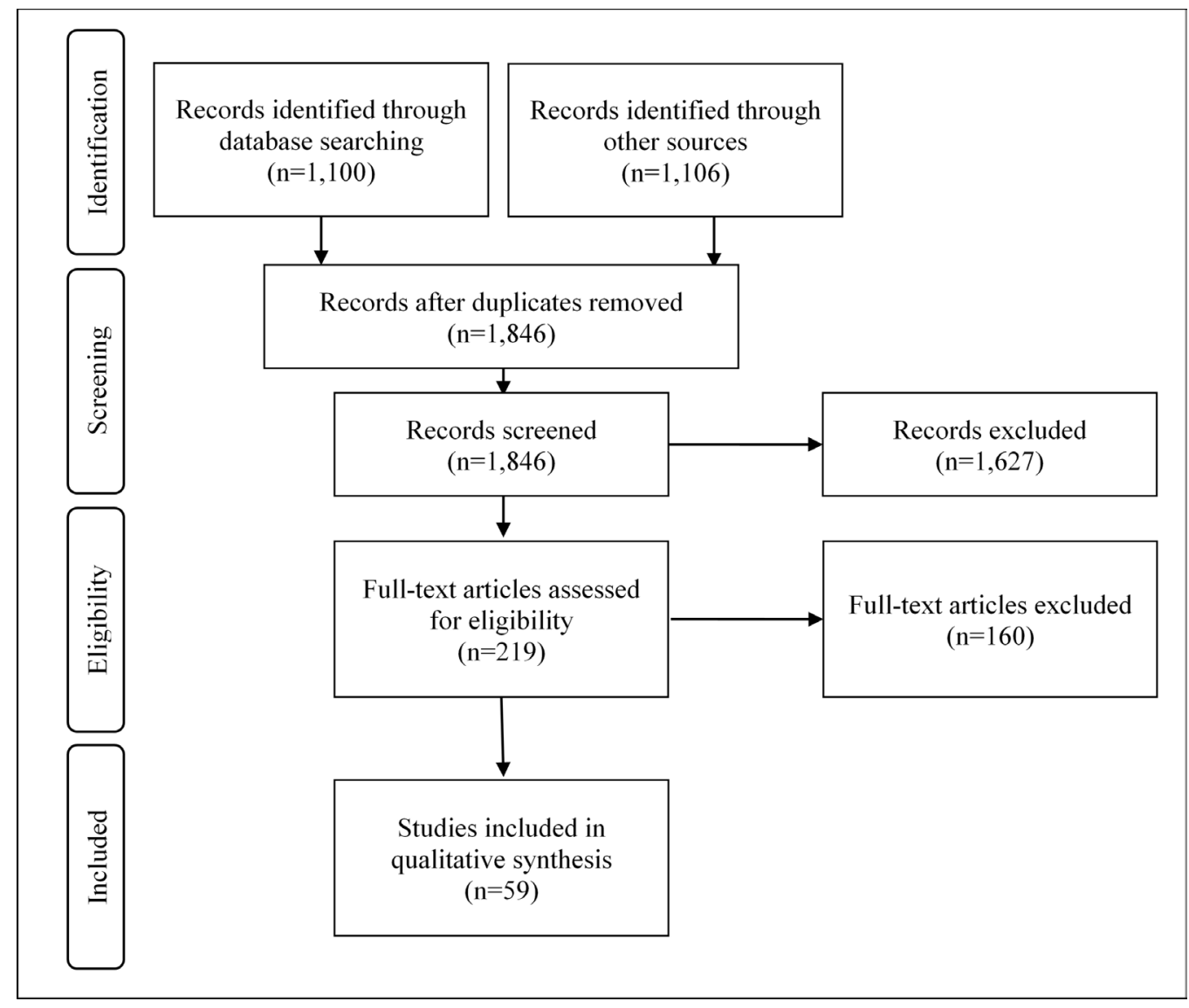

Figure 1 Preferred Reporting Items for Systematic Reviews and Meta-Analyses flow diagram. 
appendices which correspond to the synthesis of results below as follows: 'Consumption and associated factors, including prevalence' (online supplementary appendix 1; 26 articles) $)^{15}$ 24-48 'Interventions-specifically for Australian Indigenous populations' (online supplementary appendix 2; 18 articles); ${ }^{16} 27$ 30 49-63 'General population interventions which have considered Australian Aboriginal and Torres Strait Islander populations' (online supplementary appendix 3; 4 articles) ${ }^{64-67}$ and 'Observational studies' (online supplementary appendix $4 ; 13$ articles) ${ }^{68-80}$ Two articles appeared in more than one appendix table. Results reported within this review are specific to Australian Aboriginal and Torres Strait Islander people unless otherwise stated.

\section{Characteristics of included studies}

Just over half of included studies $(n=33)$ were conducted solely in remote communities, and one study collected data from both a remote and a rural town. ${ }^{39}$ Remaining articles contained data from a mixture of rural and urban settings, with only one study ${ }^{54}$ conducted solely in an urban location. Seven studies reported data from five longitudinal cohort studies; three of these reported data from one wave of the study in a cross-sectional design ${ }^{374043}$; two were longitudinal studies of mother-child dyads focused on infant feeding practices ${ }^{39}{ }^{48}$; one reported longitudinal data by age of child, ${ }^{36}$ and one reported analysis obtained from longitudinal data. ${ }^{38}$ The earliest record that met the inclusion criteria was published in 1994, reporting data from 1986 to $1989 .{ }^{57}$

\section{Consumption}

Tables 1 and 2 display SSB consumption data (also see online supplementary appendix 1 for studies containing consumption data $\left.{ }^{1524-48}\right)$. In table 1 , individual results are from self-report measures (eg, questionnaire or interview), and table 2 results are from store sales data (eg, total store sales within a remote community, divided by the estimated population for that community, to provide per capita data known as 'apparent consumption'). Self-report data include estimates of consumption prevalence (ie, the proportion of the population drinking an SSB within a specific time period such as the prior day or prior week), but store sales data do not. Both self-report and store sales data provide measures of consumption volume. Store sales data do not indicate who is purchasing a beverage as sales data are averaged across all community members including children. Most studies measured SSB consumption as part of a focus on other matters, such as determinants of obesity, community health or dental health surveys. More recent studies in remote communities have included SSB consumption measurement as a specific focus. ${ }^{27}{ }^{31}$ Only four studies included measures that provide an approximation of consumption frequency. 38404145

Table 3 summarises the different approaches used to quantify SSB consumption and reflects a wide range of measurements, which varied depending on the study design and population of interest. The heterogeneity in methods and measures impedes comparisons between studies and populations, and prohibits calculation of overall consumption prevalence, amount or frequency to determine which demographic groups consumed the most SSBs. For example, detailed beverage consumption was captured in the National Aboriginal and Torres Strait Islander Nutrition and Physical Health Survey (NATSINPAS); however, the published report combined sugar-sweetened and non-caloric drinks. ${ }^{15}$ A small selection of NATSINPAS data was published within the Australian Health Survey's (2012-2012) supplementary online tables, including consumption prevalence (defined as any consumption of the SSB on the day prior to NATSINPAS interview) by age group and gender for two SSB categories: sugar-sweetened soft drinks/flavoured mineral waters; and cordials. ${ }^{24}$ This cross-sectional data showed that statistically significant differences in prevalence by age were apparent between the two SSB categories. For cordials, consumption prevalence was highest for children aged 2-8 years, significantly decreased in the next age bracket (9-13 years) and gradually decreased (non-significantly) with each subsequent increase in age category up to 50 years. Conversely, consumption prevalence for soft drinks/flavoured mineral waters was highest for adolescents and young adults (aged 14-30 years). Compared with adolescents and young adults, consumption was non-significantly lower in adjacent age brackets (9-13 years; $31-50$ years) and significantly lower in both the youngest (2-8 years) and oldest (51 years and over) age groups. Prevalence of consumption for both SSB categories was marginally, but not statistically significantly, higher for males compared with females. Median consumption (in millilitres) was also provided, for people who had consumed the beverage type (see online supplementary appendix 1). ${ }^{24}$ These data are useful in providing a broad-brush picture of consumption for these two beverage types, but comparison with other studies and reports is limited due to the construction of variables (eg, combining sugar-sweetened and non-caloric drinks for some measures, using median rather than mean consumption). Overall, the pattern of results in tables 1 and 2 suggests that SSB consumption prevalence and amount were found to be high in most studies, and that SSBs contribute a sizeable proportion of both sugar and energy intake. Examples of studies where consumption was found to differ by demographic characteristics were those that showed lower SSB sales in some island and inland communities compared with others ${ }^{34} 42$ and lower SSB consumption prevalence in adults 51 years and over compared with other age groups. ${ }^{15}{ }^{24}$ Furthermore, a small number of studies suggest that sugary drinks are introduced to children from an early age. Five studies found that cordial or sweetened water were sometimes given to babies before age 12 months. ${ }^{36} 39404869$ One study found prevalence of SSB consumption (ie, any consumed on prior day) to be high (between $45 \%$ and 53\%) in children aged 3-9 years. ${ }^{37}$ Other cross-sectional studies have 


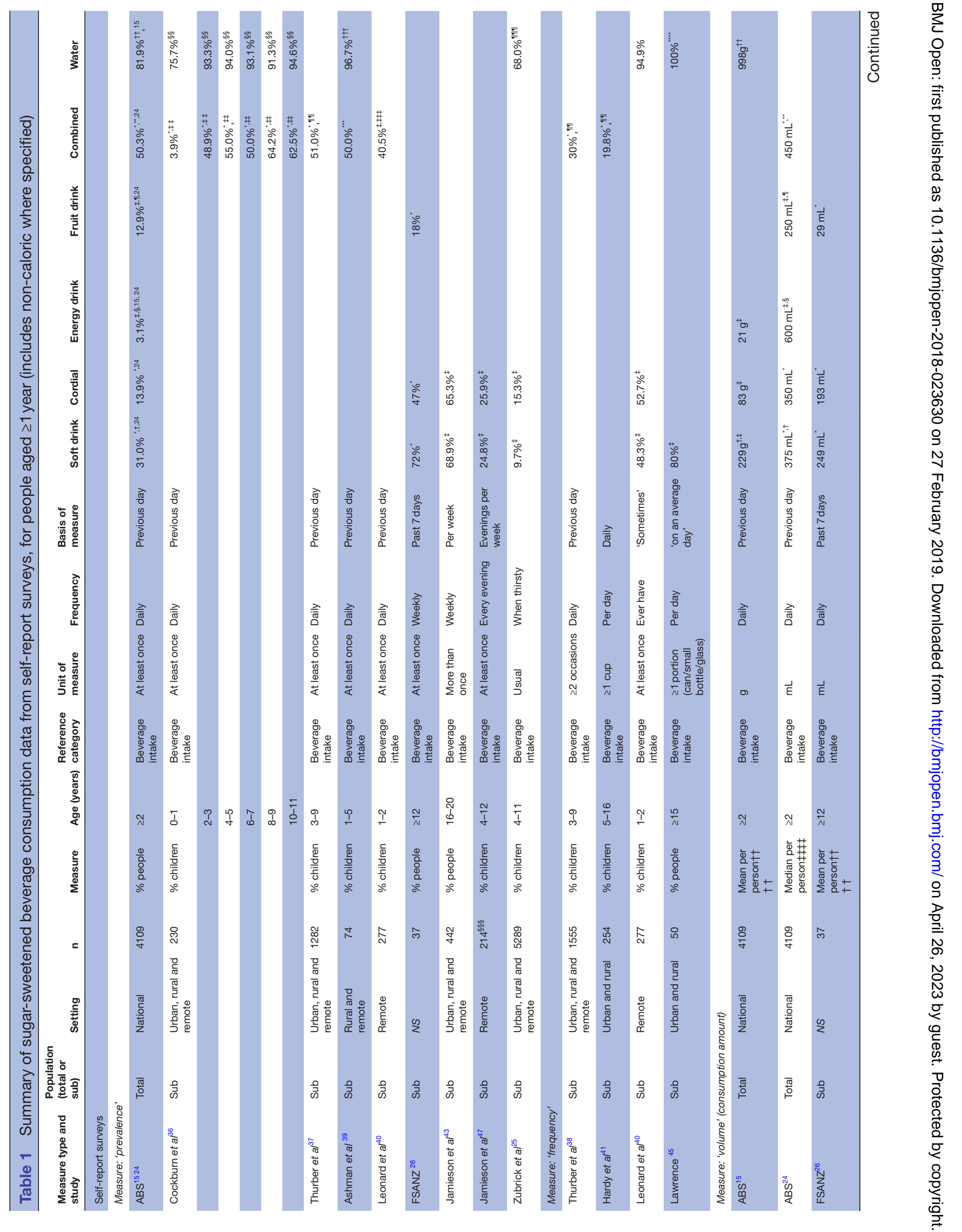




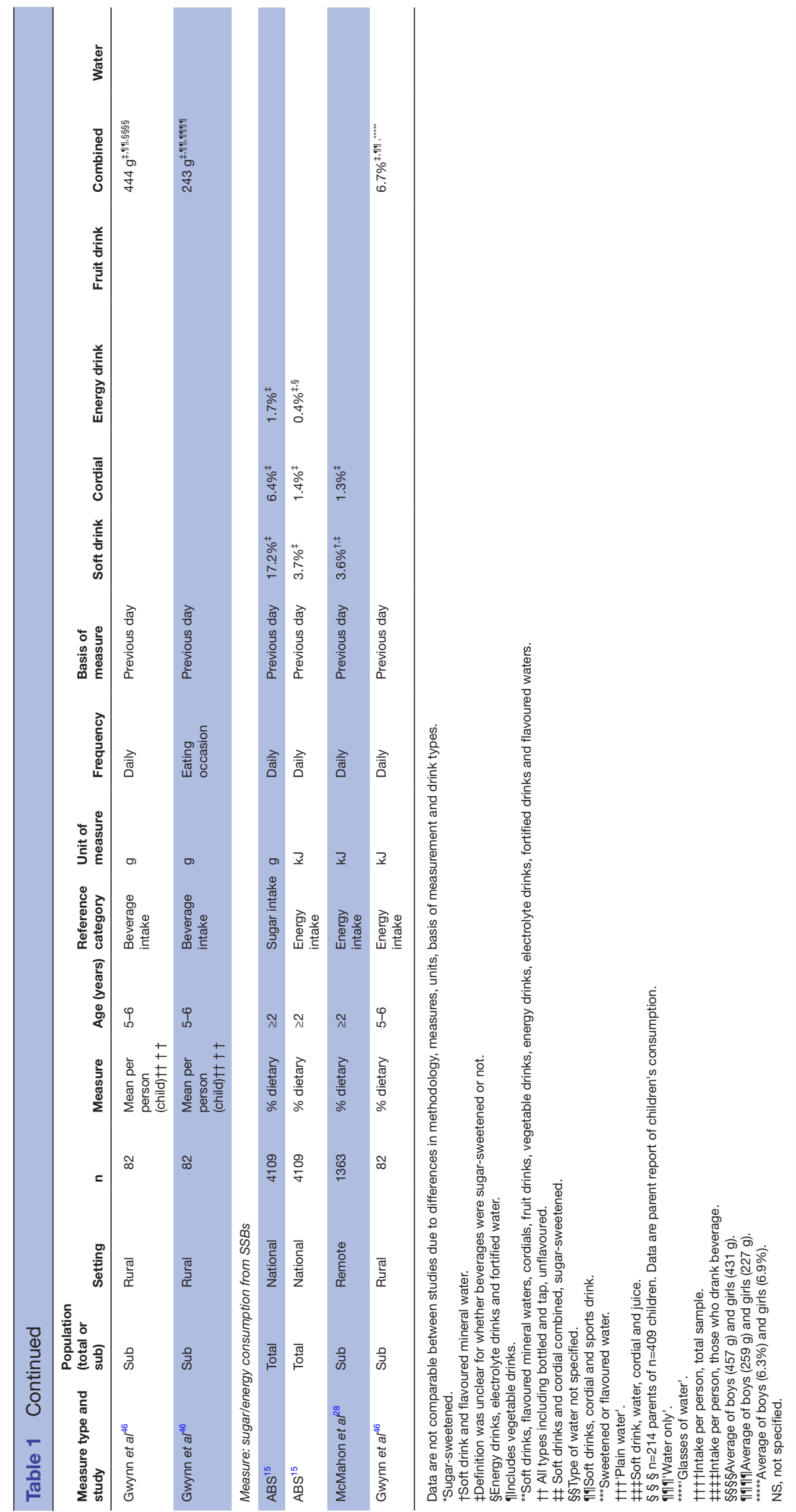

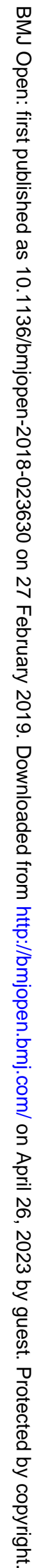




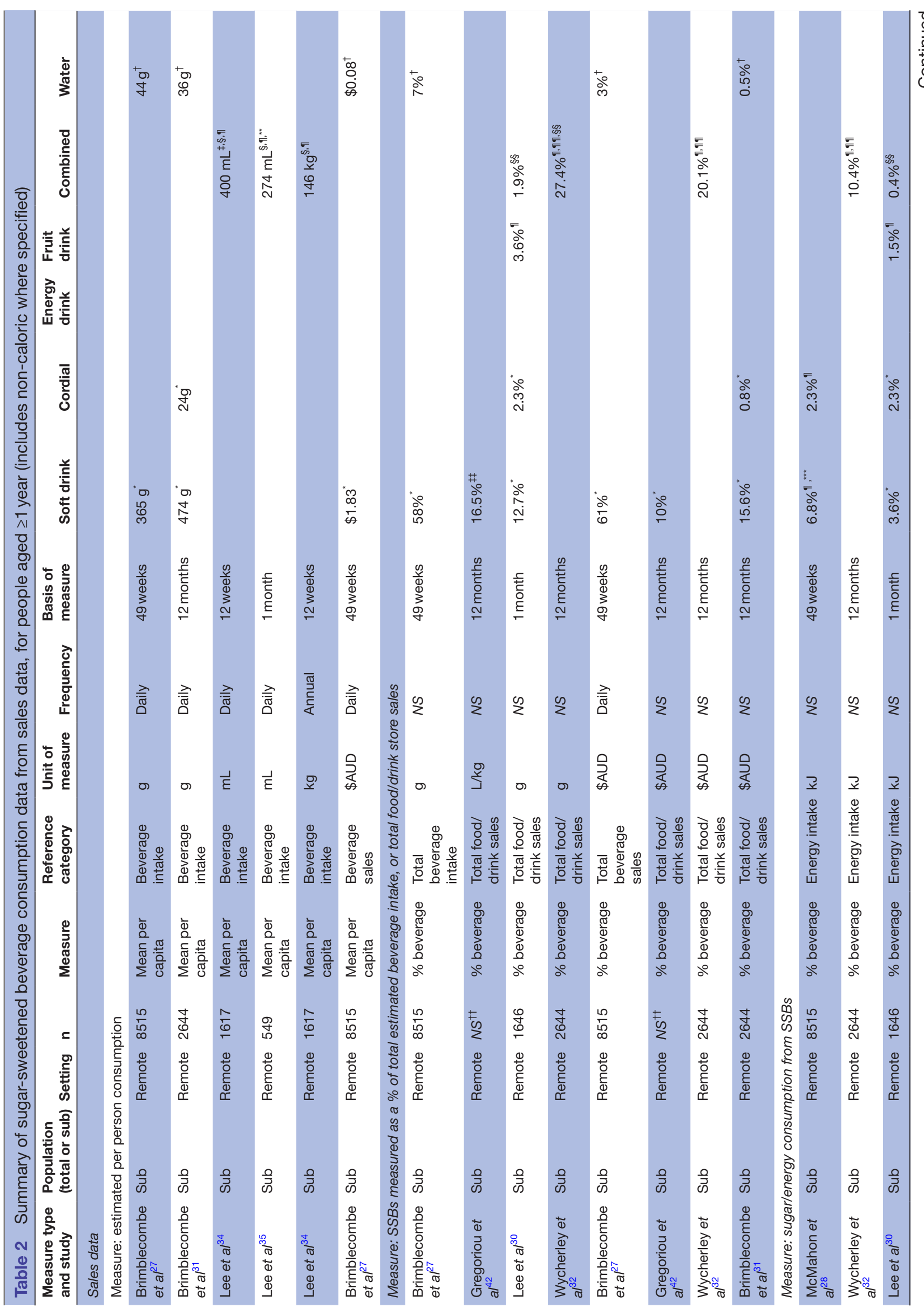




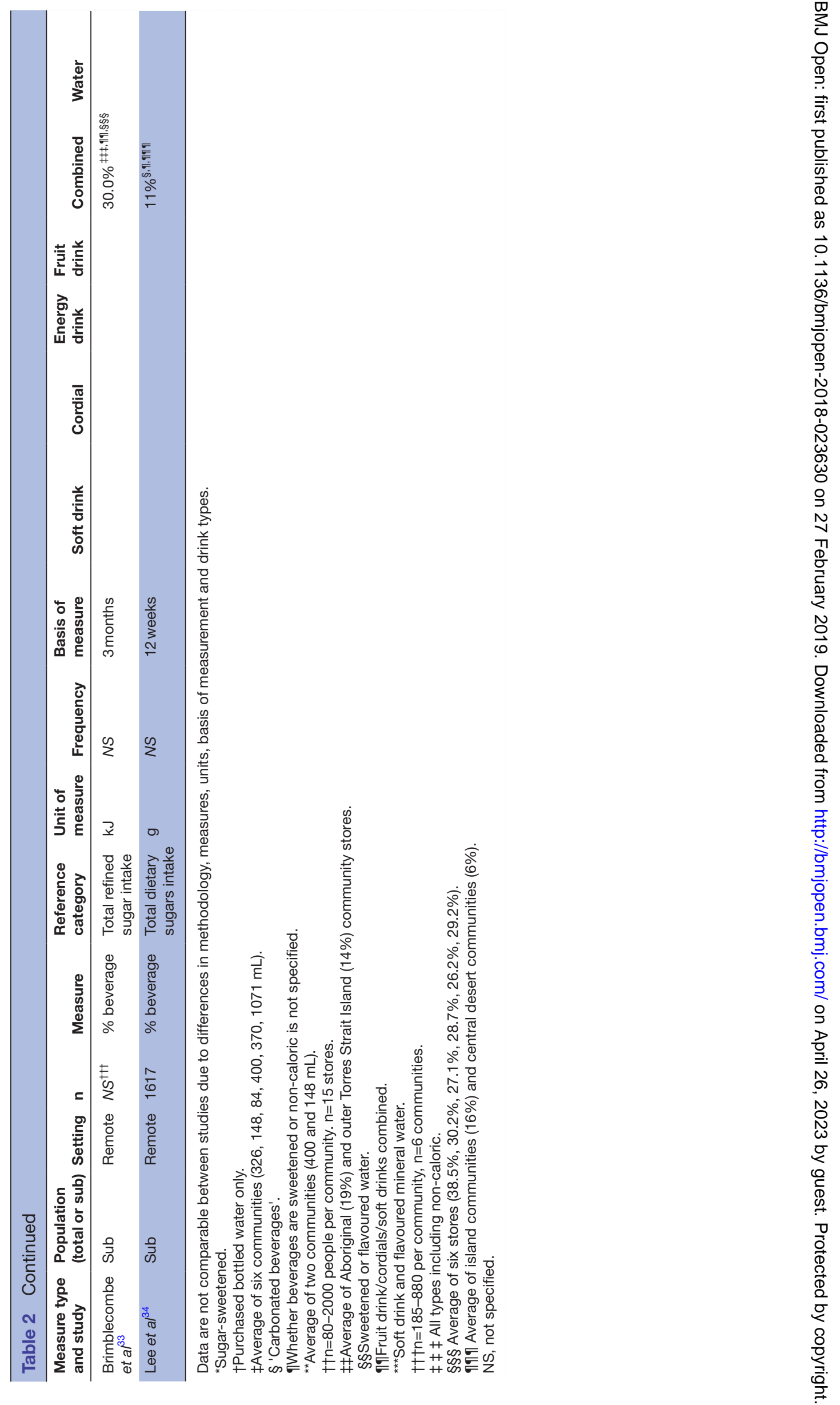


Table 3 Distribution of consumption measures by type

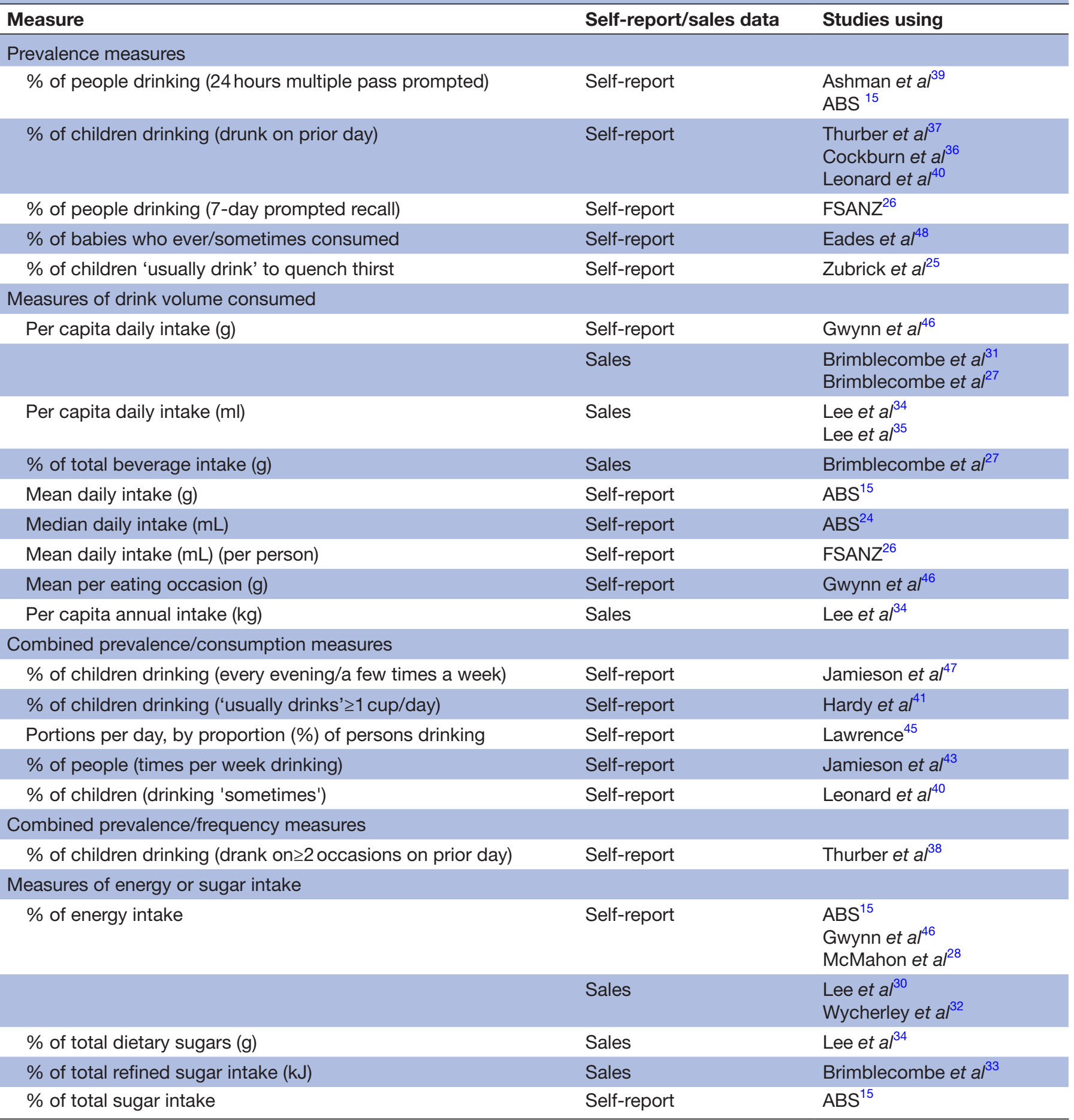

shown a pattern that cordial consumption is more prevalent during earlier childhood (compared with other age groups), whereas soft drink consumption was higher in the adolescent/teenage years. ${ }^{152425}$ Longitudinal study data would be required to determine whether this is a transition between beverages as children age or related to other factors (such as popularity of particular beverage types changing over time, eg, due to the influence of advertising campaigns). There was only one longitudinal cohort study with consumption data published by age (from 0 to 1 to $10-11$ years of age); however, consumption prevalence was combined for sugar-sweetened soft drinks and cordials, with an overall finding that consumption prevalence increased as the children grew older. ${ }^{36}$

\section{Interventions}

Interventions specifically for Aboriginal and Torres Strait Islander people

Intervention studies (see online supplementary appendix 2 for studies describing interventions ${ }^{16273049-63}$ ) were classified 
as either incentivising healthier options $(n=4)$, reducing availability of less healthy options $(\mathrm{n}=1)$, nutrition education $(n=5)$, multifaceted $(n=5)$ or policy implementation $(n=3)$. Of the 18 included intervention studies, 13 were conducted in remote communities, 1 a rural setting and the remainder being nutrition education interventions implemented in areas of South East Queensland $(n=2)^{1653}$ and Victoria $(\mathrm{n}=2){ }^{54}{ }^{55}$ Policy implementation refers to store nutrition policy and government policy.

Nutrition interventions in remote communities is a body of work that has been building progressively since the 1980s, and this review found that a small number $(n=5)$ included a measure relating to SSBs. Within these studies, it appears that considerable care has been taken for a culturally sensitive approach, many are community-driven initiatives and almost all have involved extensive community consultation and collaboration. Almost all interventions aiming to reduce SSB consumption in remote communities were implemented through the community stores, which are frequently community-owned. Earlier studies explored the effect of combining education in the community with changes in-store (such as promotion of healthier alternatives through placement at eye height and use of shelf advertising) ${ }^{57-59}$ During this time, store nutrition policies were also implemented which had implications for SSB sales. ${ }^{3061}$ The results were mixed when evaluating the change in the relative proportion of non-caloric drinks compared with SSBs sold using the store turnover method, and availability of drinking water (safe tap water or affordable bottled water) ${ }^{61}$ Nevertheless, results of store nutrition policy compliance evaluations indicate that improvements relating to SSBs have been made in the retail environments with the implementation of forty nutrition recommendations ranging from $44 \%$ to $63 \%$ across five Mai Wiru stores. ${ }^{30}$ Exact figures were not reported, but multiple stores had implemented 'removing large sizes of energy drinks and sports drinks', and 'Ensure that $>50 \%$ of SSBs stocked are $\leq 375 \mathrm{~mL}$ '.

More recent studies have explored the application of price discounts on artificially sweetened carbonated beverages and bottled water. Neither a $10 \%(n=18$ remote communities $)$ or $20 \% \quad(\mathrm{n}=20$ remote communities $)$ discount on the price of artificially sweetened soft drinks influenced the volume of these drinks sold; however, a 20\% discount on bottled water led to a $17.6 \%$ increase in the volume of water sold (but not a reduction in sugar-sweetened carbonated beverages purchased). ${ }^{27} 50$ The addition of a community-based education programme to the $20 \%$ discount strategy also had no effect on sales of water, artificially sweetened or SSBs. ${ }^{27}$ The authors of the latter randomised controlled trial (RCT) argue that the results suggest that instead of discounting healthier alternatives making SSBs more expensive may be more effective in reducing SSB purchases, and this could be achieved through systematic price increases via taxation or store policies. They recommended that future studies trial price increases on high-sugar products, rather than discounts on alternatives. ${ }^{27} \mathrm{~A}$ smaller substudy within this trial explored potential mediators and moderators of behaviour change related to SSB consumption in communities which received the $20 \%$ discount plus the nutrition education intervention. ${ }^{49}$ Neither self-efficacy (belief that participants could change their beverage consumption) nor food insecurity (running out of money to purchase food) influenced the relationship between pre-intervention and post-intervention consumption volume.

The intervention study reporting the greatest reduction in SSB sales was a retrospective evaluation of a community-led decision to remove the three highest selling sugar-sweetened soft drinks from sale in their community store. ${ }^{52}$ The community made this decision based on concerns about the health consequences of poor diet. The evaluation found a $50 \%$ reduction in the volume of sugar-sweetened soft drinks sales, which resulted in a reduction in sugar and kilojoules available to be consumed through SSBs. ${ }^{52}$ Despite reductions in SSBs sales, the local business remained unaffected as the volume of total beverage sales remained constant.

Two articles evaluated the 'Rethink Sugary Drinks' online and television advertising campaign, which aimed to reach Aboriginal and Torres Strait Islander people. ${ }^{1653}$ Attitudes towards the advertising were positive, with most respondents agreeing that it communicated an important message that was relevant to them. ${ }^{1653}$ Correct identification of the sugar content of soft drinks was similar among those who had, and those who had not, seen the ad, in both evaluations (ie, there was not a significant difference between groups in either evaluation, with correct identification ranging from $49 \%$ to $63 \%$ in one study, and from $43 \%$ to $55 \%$ in the second study). ${ }^{1653}$ Of those who had seen the ad, more than half reported drinking less sugary drinks (no comparison is available for those who had not viewed the ad). ${ }^{1653}$ Another evaluation was of a 7-week school education programme $(90 \mathrm{~min}$ lessons per week) among urban Aboriginal and Torres Strait Islander adolescents. ${ }^{54}$ All participants were surveyed immediately prior to the first session and following the final session. Programme participants were more likely to correctly identify the sugar content in soft drinks compared with a control group; however, neither between-group or within-group self-reported soft drink consumption had changed after completing the 7 -week programme. ${ }^{54}$

\section{Interventions targeting the general population}

Three intervention studies targeted the general population and considered implementation or evaluation in Australian Aboriginal and Torres Strait Islander populations (see online supplementary appendix 3 for full study details). Both the "New South Wales Get Healthy Information and Coaching Service ${ }^{, 64} 65$ and the 'Good for Kids, Good for Life' programme reports ${ }^{66}$ provide detailed descriptions of efforts to consult and include Aboriginal and Torres Strait Islander people in programme design, implementation and evaluation. However, none of the studies published outcome data for Aboriginal and Torres Strait Islander people separately to the general population data. The 'Go4Fun' community-based childhood obesity 
treatment evaluation found that Aboriginal and Torres Strait Islander children were less likely to complete the programme than non-Indigenous children, and therefore recommended that a specific, more culturally appropriate programme should be developed for Aboriginal and Torres Strait Islander children. ${ }^{67}$

\section{Observational studies}

Several studies were identified which met the inclusion criteria, but did not directly measure consumption or evaluate an intervention (see online supplementary appendix 4).${ }^{68-80}$ Four qualitative studies provided themes which are congruent with previously discussed results: community members, parents and healthcare workers identified SSB consumption in adults and children as being a problem, ${ }^{68-70} 79$ and expressed concerns that children were reliant on 'sweet drinks' ${ }^{69}$ These studies also discussed the influence of Aboriginal and Torres Strait Islander children in purchasing decision-making, that in some communities children may have more of a role in decision-making than in the broader Australian population and that it can be hard for parents to say no to requests for 'fizzy drinks' (soft drinks). ${ }^{68-70} 79$ One qualitative study in a remote community found that a common explanation for junk food consumption (including soft drinks) was that it is a habitual behaviour, formed during mission times when packet sugar was a staple food provided by missions. ${ }^{70}$ Only one included study evaluated the presence of SSB brand advertising, conducted almost 20 years ago in four New South Wales non-remote communities which had a large proportion of Aboriginal and Torres Strait Islander people. ${ }^{75}$ It found that outdoor and in-store advertising was common for SSBs.

One quantitative study compared the price differential for beverages between remote stores and urban supermarkets in $2013 .{ }^{71}$ Compared with urban supermarkets, in remote stores carbonated soft drinks were more expensive but branded bottled water was cheaper. Furthermore, the price differential between remote and urban stores was lower for diet soft drinks compared with sugar-sweetened (ie, there was a lower mark-up for diet soft drinks compared with sugar-sweetened). The authors state that these results are likely to be a consequence of a sustained effort over many years to improve pricing of healthier beverages in remote community stores.

\section{DISCUSSION}

Overall, this review has highlighted that SSBs are readily available, are a significant contributor to energy intake and that this is of concern to community members. There is evidence of high SSB consumption prevalence and volume. It was not possible to provide systematic comparisons of consumption across demographic and geographic subgroups. This was due to heterogeneity of methods and measures assessing consumption, and partial reporting of detailed consumption data for SSBs separately to non-caloric beverages in national surveys. However, the data suggest that consumption of sugary drinks occurs at an early age; young children drink cordial at higher levels than adults, whereas soft drink consumption prevalence is highest among adolescents and young adults. It is also subjectively clear from the data that it is only in recent years that SSB consumption has become a specific focus for consumption measurement and targeted interventions.

Few studies have directly observed existing personal, social and environmental influencers of SSB consumption in Aboriginal and Torres Strait Islander populations, whether in urban, rural or remote settings. Nevertheless, environmental influencers contributing to SSB consumption can be interpreted from intervention studies, where strategies to change price and availability have been trialled. The majority of this work has been completed in remote communities. An evaluation of the relative effectiveness of different interventions was outside of the scope of this study. The review did show that study aims, types of interventions trialled and measurement of outcomes varied, suggesting that there are multiple angles from which the problem of overconsumption of SSBs can be addressed. During analysis it appeared subjectively clear that the most conclusive results of intervention research to date were that SSB sales were influenced by in-store availability, ${ }^{52}$ but were not influenced by a price discount on healthier alternatives (bottled water and artificially sweetened drinks) even though price discounts did increase the sale of bottled water. ${ }^{27} 50$ Aboriginal and Torres Strait Islander leaders in communities have advocated for community stores to play an important role in trialling and implementing strategies to reduce sales of SSBs, and promote healthier alternatives such as bottled water, for example, through participation in RCTs of pricing strategies, and implementation of nutrition policies. The store's preparedness to balance the health needs of the community with commercial objectives is somewhat unique, and admirable in a commercial environment. This situation is made feasible because the organisations that own and run these community stores have set a key goal of providing nutritious food in order to improve community health, supported by systems and policies aiming to ensure that the viability of the store does not compromise food security for the community. ${ }^{81}$ Furthermore, the majority of stores in remote Indigenous community have an ownership structure that is either community-based or involves redirection of profits back into the community. ${ }^{82}$

Fewer interventions have been implemented with Aboriginal and Torres Strait Islander people living in non-remote areas. Those that have been implemented have typically involved health education (through advertising, in-school programmes or public events), and although some did result in improved awareness of the sugar content of soft drinks, the impact on self-reported SSB consumption was either unclear or there was no change. ${ }^{16354}$ This finding confirms that although knowledge is well recognised as one important factor underpinning behaviour change, other factors that are key 
determinants of an individual's capacity to change their consumption behaviour (eg, personal, environmental and/or social factors) must also be considered, for interventions to reduce SSB intake to be effective. The role of habit, product packaging, in-store cues, and branded marketing and media campaigns were all identified as factors on food choice in remote communities. ${ }^{79}$ It is likely that they also influence food choices such as sugary drinks in non-remote settings. Only a small number of interventions that target the general population have considered implementation for Aboriginal and Torres Strait Islander people, and have demonstrated the importance of taking a specific, culturally sensitive approach. ${ }^{64-67}$

These results suggest that exploring individual and social factors relating to environmental characteristics is important. There is some evidence from qualitative studies that the role of children may be important in purchase decision-making. ${ }^{68-70} 79$ Whereas self-efficacy and food security were unrelated to post-intervention SSB consumption in another study. ${ }^{27}$ Further research is needed to understand the modifiable personal, social and environmental influencers that are associated with SSB consumption. There is an emerging literature on the application of enviro-psycho-social behaviour change frameworks to reducing SSB consumption ${ }^{83-85}$ which may be useful in the development of future interventions when used in conjunction with health inequality frameworks and notions of Indigenous health. ${ }^{34}$ Application of such frameworks may help with developing strategies to reduce SSB consumption as part of a broader, holistic strategy to improve nutrition and reduce the prevalence of chronic preventable disease. Indeed, a number of environmental influencers of chronic disease risk for Indigenous communities (worldwide) were examined in a review by Daniel $e t a l,{ }^{86}$ with many of the relationships likely to be mediated, at least in part, by adverse dietary quality factors such as SSB consumption.

There are several opportunities for future research that follow from this review. Extracting additional SSB-specific consumption data from the ABS' nationally representative survey of Aboriginal and Torres Strait Islander people (NATSINPAS ${ }^{15}$ could provide highly detailed information on consumption within and between demographic subgroups around Australia, and provide a benchmark for measurement of change for any future interventions. Related to this, where interventions that target the general population have included a specific focus on Aboriginal and Torres Strait Islander people, it would be useful for reporting to include the impact on consumption behaviour, and health outcomes, for Indigenous Australians. Within remote communities, trialling price increases on SSBs would be a logical next step from the recent price discount trials on non-caloric alternative beverages (bottled water, and artificially sweetened drinks), ${ }^{2750}$ and this would inform decisions as to whether systematic price increases via taxation or store policies could be implemented, and/or the required level of price increase required. However, when reviewing pricing as a strategy, consideration could also be given to other factors influencing consumption, based on evidence from other studies. This evidence includes the effectiveness of the community-led decision to remove the top-selling SSBs from sale within the community store, ${ }^{52}$ and the importance of community preferences, consultation and collaboration. The question of how to reduce SSB consumption in non-remote areas is a significant gap in knowledge. Interventions in non-remote areas are likely to require a different approach to remote communities due in part to the geographical and environmental differences. Related to this, identifying the personal, social and environmental factors influencing SSB consumption in remote, rural and urban communities will be an important step to assist in planning approaches to influence SSB purchases and consumption. Finally, in the future it will be important to develop a consistent, and culturally appropriate, set of measures of consumption, for results to be compared across time, and between individual studies.

In taking a broad, systematic approach to scoping the literature, this review was able to bring together SSB data from a diverse range of sources. Given the considerable number of included studies, and variety of sources, capturing available data in one document is likely to be useful to researchers, communities and policymakers. One limitation is that an appraisal of quality was not included. Although this non-inclusion is appropriate for a systematic scoping review, during analysis it was subjectively clear that there was variability in the quality of included studies. To help clarify this, details of methods are provided in the supplementary tables, to highlight where quality may be low. Examples include small sample sizes, sampling methods which provided representative data of the broader national Australian population but not of the national Indigenous population; and incomplete details on methodology. Within the inclusion criteria, studies that targeted dietary improvements, but did not provide data specific to SSBs, were excluded. This may have meant that information from interventions which influenced food and drink choices more broadly was not captured, and these may also have influenced SSB consumption.

In conclusion, this systematic scoping review has provided a detailed overview of existing data regarding SSB consumption in the Australian Aboriginal and Torres Strait Islander population. Opportunities for future studies include RCTs of price increases on SSBs in remote communities, analysis and reporting of the detailed consumption data captured in national health surveys, and development of a consistent set of measures of consumption (to allow for comparisons over time and between studies). The story of high sugary drink consumption is not unique to Aboriginal and Torres Strait Islander populations as it is also known that consumption is high in the general population and in many countries around the world. ${ }^{24}{ }^{87}$ However, the studies included in this systematic scoping review have clearly highlighted that taking a culturally sensitive approach to any measurement or 
intervention work with Australian Indigenous populations is of critical importance as the most successful interventions have either been community-driven or involved extensive community consultation and collaboration. Future research in this area should continue to build on this as it is a key strength of the literature and an important requirement for ethical research within these populations and communities. ${ }^{6}$

\section{Author affiliations}

${ }^{1}$ Population Health Research Group, South Australian Health and Medical Research Institute, Adelaide, South Australia, Australia

${ }^{2}$ School of Psychology, The University of Adelaide, Adelaide, South Australia, Australia

${ }^{3}$ School of Public Health, The University of Adelaide, Adelaide, South Australia, Australia

${ }^{4}$ Wardliparingga Aboriginal Research Unit, South Australian Health and Medical Research Institute, Adelaide, South Australia, Australia

${ }^{5}$ Sansom Institute, University of South Australia, Adelaide, South Australia, Australia ${ }^{6}$ School of Health Sciences, University of South Australia, Adelaide, South Australia, Australia

${ }^{7}$ Health Translation SA, Adelaide, South Australia, Australia

${ }^{8}$ Adelaide Medical School, The University of Adelaide, Adelaide, South Australia, Australia

Acknowledgements Jaime Royal (Research Librarian, The University of Adelaide) provided expertise for the literature search strategy.

Contributors JAB, CLM, JD and DR conceived the idea for the project. JCA, $\mathrm{JB}, \mathrm{JD}, \mathrm{OG}, \mathrm{WK}$ and CLM developed the research question. JD, CLM, and ALB provided expertise on sugar sweetened beverages. $O G$ and WK provided expertise in Aboriginal and Torres Strait Islander research, the relevance of the research direction and method to answer the question. KO and TPW provided expertise in dietary intake research in Aboriginal and Torres Strait Islander communities. JCA drafted the protocol manuscript. KMW conducted literature searches, screening, data extraction, data synthesis, writing of manuscript and coordination of manuscript editing. ALB assisted with the preliminary literature search, grey literature searches and data extraction. JD and JAB provided strategic input for data synthesis. All authors read, provided critical review and approved the manuscript.

Funding This work was supported by the University of South Australia and the NHMRC Program Grant no. 631947.

Competing interests None declared.

Patient consent for publication Not required.

Provenance and peer review Not commissioned; externally peer reviewed.

Data sharing statement № additional unpublished data are available.

Open access This is an open access article distributed in accordance with the Creative Commons Attribution Non Commercial (CC BY-NC 4.0) license, which permits others to distribute, remix, adapt, build upon this work non-commercially, and license their derivative works on different terms, provided the original work is properly cited, appropriate credit is given, any changes made indicated, and the use is non-commercial. See: http://creativecommons.org/licenses/by-nc/4.0/.

\section{REFERENCES}

1. World Health Organization. Global action plan for the prevention and control of noncommunicable diseases 2013-2020. Geneva, Switzerland: World Health Organization, 2013.

2. Australian Health Ministers' Advisory Council. Aboriginal and Torres Strait Islander health performance framework 2017 report. Canberra: Australian Health Ministers' Advisory Council, 2017.

3. Gracey M, King M. Indigenous health part 1: determinants and disease patterns. Lancet 2009;374:65-75.

4. King M, Smith A, Gracey M. Indigenous health part 2: the underlying causes of the health gap. Lancet 2009;374:76-85.

5. Burrow S, Ride K. Review of diabetes among Aboriginal and Torres Strait Islander People. Mt Lawley, Australia: Edith Cowan University Australian Indigenous HealthInfoNet, 2016.
6. King R, Brown A. Next steps for Aboriginal health research: exploring how research can improve the health and wellbeing of Aboriginal people in South Australia. Adelaide: Aboriginal Health Council of South Australia, 2015.

7. World Health Organization. Global report on diabetes. Geneva, Switzerland: World Health Organization, 2016.

8. Australian Bureau of Statistics. Australian Aboriginal and Torres Strait Islander health survey: Biomedical results, 2012-13, Cat. No. 4727.0.55.003. Canberra, Australia: Australian Bureau of Statistics, 2014.

9. Australian Bureau of Statistics Australian Aboriginal and Torres Strait Islander health survey: Updated results, 2012-13, Cat. No. 4727.0.55.006. Canberra, Australia Australian Bureau of Statistics 2014.

10. Vartanian LR, Schwartz MB, Brownell KD. Effects of soft drink consumption on nutrition and health: a systematic review and metaanalysis. Am J Public Health 2007;97:667-75.

11. Malik VS, Pan A, Willett WC, et al. Sugar-sweetened beverages and weight gain in children and adults: a systematic review and metaanalysis. Am J Clin Nutr 2013;98:1084-102.

12. Malik VS, Popkin BM, Bray GA, et al. Sugar-sweetened beverages and risk of metabolic syndrome and type 2 diabetes: a metaanalysis. Diabetes Care 2010;33:2477-83.

13. Heise TL, Katikireddi SV, Pega F, et al. Taxation of sugar-sweetened beverages for reducing their consumption and preventing obesity or other adverse health outcomes. Cochrane Database Syst Rev 2016;8.

14. Australian Bureau of Statistics. Australian health survey: Nutrition first results - foods and nutrients, 2011-12, cat no. 4364.0.55.007. Canberra, Australia: Australian Bureau of Statistics, 2014.

15. Australian Bureau of Statistics. National Aboriginal and Torres Strait Islander health survey: Nutrition results - foods and nutrients, 201213, Cat. No. 4727.0.55.005. Canberra, Australia: Australian Bureau of Statistics, 2015.

16. Egan M, MacDonald C, Browne J, et al; You wouldn't eat 16 teaspoons of sugar-so why drink it? Community response to the Aboriginal rethink sugary drink ad online. In: Tapsell L, ed. Nutrition and Dietetics 2016: Proceedings of the Dietitians Association of Australia 33rd National Conference Melbourne, Australia, 2016.

17. Avery JC, Bowden JA, Dono J, et al. Sugar-sweetened beverage consumption, correlates and interventions among Australian Aboriginal and Torres Strait Islander communities: a scoping review protocol. BMJ Open 2017;7:e016431

18. van der Sterren A, Greenhalgh E, Knoche D, et al. Tobacco action initiatives targeting Aboriginal Peoples and Torres Straits Islanders Melbourne, Australia: Cancer Council Victoria, 2016.

19. Northern Territory Government. Aboriginal cultural security framework 2016 - 2026. Northern Territory, Australia: Northern Territory Health, 2016.

20. Arksey H, O'Malley L. Scoping studies: towards a methodological framework. Int J Soc Res Methodol 2005;8:19-32.

21. Levac D, Colquhoun H, O'Brien KK. Scoping studies: advancing the methodology. Implement Sci 2010;5:69.

22. National Health and Medical Research Council. Eat for health: Australian dietary guidelines summary. Canberra, Australia: Australian Government Department of Health and Ageing, 2013.

23. Clarivate Analytics. Endnote. Version x8. 2016;.

24. Australian Bureau of Statistics. Australian health survey: Nutrition first results - foods and nutrients, 2011-12 - Australia, 'table 18: Consumption of sweetened beverages', data cube: Excel spreadsheet, Cat. No. 43640do001_20112012. Canberra, Australia: Australian Bureau of Statistics, 2014.

25. Zubrick S, Lawrence D, Silburn S, et al. The Western Australian Aboriginal child health survey: The health of Aboriginal children and young people. Perth, Australia: Telethon Institute for Child Health Research, 2004.

26. Food Standards Australia New Zealand. Consumption of intense sweeteners in Australia and New Zealand - Roy Morgan research report. Canberra: Food Standards Australia New Zealand, 2003.

27. Brimblecombe J, Ferguson M, Chatfield MD, et al. Effect of a price discount and consumer education strategy on food and beverage purchases in remote Indigenous Australia: a steppedwedge randomised controlled trial. Lancet Public Health 2017;2:e82-e95.

28. McMahon E, Wycherley T, O'Dea K, et al. A comparison of dietary estimates from the National Aboriginal and Torres Strait Islander Health Survey to food and beverage purchase data. Aust N Z J Public Health 2017;41:598-603.

29. Lee AJ, Sheard JStore nutrition report. Final store turnover food and nutrition results. Nganampa Health Council. 2013. 
30. Lee A, Rainow S, Tregenza J, et al. Nutrition in remote Aboriginal communities: lessons from Mai Wiru and the Anangu Pitjantjatjara Yankunytjatjara Lands. Aust N Z J Public Health 2016;40:S81-8.

31. Brimblecombe JK, Ferguson MM, Liberato SC, et al. Characteristics of the community-level diet of Aboriginal people in remote northern Australia. Med J Aust 2013;198:380-4.

32. Wycherley TP, Pekarsky BA, Ferguson MM, et al. Fluctuations in money availability within an income cycle impacts diet quality of remote Indigenous Australians. Public Health Nutr 2017;20:1431-40.

33. Brimblecombe J, Liddle R, O'Dea K. Use of point-of-sale data to assess food and nutrient quality in remote stores. Public Health Nutr 2013;16:1159-67.

34. Lee AJ, O'Dea K, Mathews JD. Apparent dietary intake in remote Aboriginal communities. Aust J Public Health 1994;18:190-7.

35. Lee AJ, Smith A, Bryce S, et al. Measuring dietary intake in remote Australian Aboriginal communities. Ecol Food Nutr 1995;34:19-31.

36. Cockburn N, Lalloo R, Schubert L, et al. Beverage consumption in Australian children. Eur J Clin Nutr 2018;72:401-9.

37. Thurber K, Bagheri N, Banwell C. Social determinants of sugarsweetened beverage consumption in the longitudinal study of Indigenous children. Fam Matters 2014;95:51-61.

38. Thurber KA, Dobbins T, Neeman T, et al. Body mass index trajectories of Indigenous Australian children and relation to screen time, diet, and demographic factors. Obesity 2017;25:747-56.

39. Ashman AM, Collins CE, Weatherall LJ, et al. Dietary intakes and anthropometric measures of Indigenous Australian women and their infants in the Gomeroi gaaynggal cohort. J Dev Orig Health Dis 2016;7:481-97.

40. Leonard $\mathrm{D}$, Aquino $\mathrm{D}$, Hadgraft $\mathrm{N}$, et al. Poor nutrition from first foods: A cross-sectional study of complementary feeding of infants and young children in six remote Aboriginal communities across northern Australia. Nutr Diet 2017;74:436-45.

41. Hardy LL, O'Hara BJ, Hector D, et al. Temporal trends in weight and current weight-related behaviour of Australian Aboriginal schoolaged children. Med J Aust 2014;200:667-71.

42. Gregoriou A, Leonard D. Rist: Evaluation of the remote Indigenous stores and takeaways resources in Queensland and the Anangu Pitjantjatjara Yankunytjatjara lands of South Australia. Cairns: Queensland Health, 2010.

43. Jamieson LM, Sayers SM, Roberts-Thomson KF. Associations between oral health and height in an Indigenous Australian birth cohort. Community Dent Health 2013;30:58-64.

44. Jamieson LM, Roberts-Thomson KF, Sayers SM. Risk indicators for severe impaired oral health among Indigenous Australian young adults. BMC Oral Health 2010;10:10:1

45. Lawrence CG. Influences on food and lifestyle choices for Aboriginal and Torres Strait Islander Australians: An Aboriginal perspective. Sydney, Australia: University of Sydney, 2015.

46. Gwynn JD, Flood VM, D'Este CA, et al. Poor food and nutrient intake among Indigenous and non-Indigenous rural Australian children. BMC Pediatr 2012:12:12(1):12.

47. Jamieson LM, Bailie RS, Beneforti M, et al. Dental self-care and dietary characteristics of remote-living Indigenous children. Rural Remote Health 2006;6:503.

48. Eades SJ, Read AW, McAullay D, et al. Modern and traditional diets for Noongar infants. J Paediatr Child Health 2010;46:398-403.

49. Brimblecombe J, Ferguson M, Barzi F, et al. Mediators and moderators of nutrition intervention effects in remote Indigenous Australia. Br J Nutr 2018;119:1424-33.

50. Ferguson M, O'Dea K, Holden S, et al. Food and beverage price discounts to improve health in remote Aboriginal communities: mixed method evaluation of a natural experiment. Aust N Z J Public Health 2017;41:32-7.

51. Magnus A, Moodie ML, Ferguson M, et al. The economic feasibility of price discounts to improve diet in Australian Aboriginal remote communities. Aust N Z J Public Health 2016;40(S1):S36-S41.

52. Butler R, Tapsell L, Lyons-Wall P. Trends in purchasing patterns of sugar-sweetened water-based beverages in a remote Aboriginal community store following the implementation of a communitydeveloped store nutrition policy. Nutrition \& Dietetics 2011;68:115-9.

53. MacDonald C, Browne J, Delbridge R, et al. You wouldn't eat 16 teaspoons of sugar-so why drink it? Community response to the Aboriginal rethink sugary drink advertisement. Brisbane, Australia: Australian \& New Zealand Obesity Society Annual Scientific Meeting, 2016.

54. Malseed C, Nelson A, Ware R. Evaluation of a School-Based Health Education Program for Urban Indigenous Young People in Australia. Health 2014:06:587-

55. Malseed C, Nelson A, Ware R, et al. Deadly Choices ${ }^{\mathrm{TM}}$ community health events: a health promotion initiative for urban Aboriginal and Torres Strait Islander people. Aust J Prim Health 2014;20:379-83.
56. Ju X, Brennan D, Parker E, et al. Efficacy of an oral health literacy intervention among Indigenous Australian adults. Community Dent Oral Epidemiol 2017;45:413-26.

57. Lee AJ, Bailey AP, Yarmirr D, et al. Survival tucker: improved diet and health indicators in an Aboriginal community. Aust $J$ Public Health 1994;18:277-85.

58. Lee AJ, Bonson APV, Yarmirr D, et al. Sustainability of a successful health and nutrition program in a remote Aboriginal community. Med J Aust 1995;162:632-5.

59. Scrimgeour D, Rowse T, Knight S. Food-purchasing behaviour in an Aboriginal community. 2. Evaluation of an intervention aimed at children. Aust J Public Health 1994:18:67-70.

60. Roberts-Thomson KF, Slade GD, Bailie RS, et al. A comprehensive approach to health promotion for the reduction of dental caries in remote Indigenous Australian children: a clustered randomised controlled trial. Int Dent J 2010;60:245-9.

61. Lee AJ, Hobson V, Katarski L. Review of the nutrition policy of the Arnhem Land Progress Association. Aust N Z J Public Health 1996;20:538-44.

62. McLean E, Annat K, Lee A. Store nutrition report and market basket survey Nganamapa Health Council. 2014.

63. Brimblecombe JK, McDonnell J, Barnes A, et al. Impact of income management on store sales in the Northern Territory. Med J Aust 2010;192:549-54.

64. O'Hara BJ, Phongsavan P, McGill B, et al. NSW get healthy information and coaching service: The first five years 2009-2013. University of Sydney: NSW Ministry of Health \& Prevention Research Collaboration, 2014.

65. O'Hara BJ, Phongsavan P, Rissel C, et al. Role of general practice in the utilisation of the NSW Get Healthy Information and Coaching Service. Aust J Prim Health 2015;21:182-8.

66. Wiggers J, Wolfenden L, Campbell E, et al. Good for kids, good for life 2006-2010: Evaluation report. Sydney, Australia: NSW Government, 2013.

67. Hardy LL, Mihrshahi S, Gale J, et al. Translational research: are community-based child obesity treatment programs scalable? BMC Public Health 2015;15:652.

68. Colles SL, Maypilama E, Brimblecombe J. Food, food choice and nutrition promotion in a remote Australian Aboriginal community. Aust J Prim Health 2014;20:365-72.

69. Myers J, Thorpe S, Browne J, et al. Early childhood nutrition concerns, resources and services for Aboriginal families in Victoria. Aust N Z J Public Health 2014;38:370-6.

70. Smith $D$, Mununggurr L, Bamundurruwuy $\mathrm{D}$, et al. How children grow: Indigenous and health professional perceptions Cooperative Research Centre for Aboriginal and Tropical Health, Darwin. 2003

71. Ferguson M, O'Dea K, Chatfield M, et al. The comparative cost of food and beverages at remote Indigenous communities, Northern Territory, Australia. Aust N Z J Public Health 2016;40:S21-6.

72. Brimblecombe J, O'Dea K. The role of energy cost in food choices for an Aboriginal population in northern Australia. Med J Aust 2009;190:549-51.

73. Gwynn JD, Flood VM, D'Este CA, et al. The reliability and validity of a short FFQ among Australian Aboriginal and Torres Strait Islander and non-Indigenous rural children. Public Health Nutr 2011;14:388-401.

74. Tonkin E, Kennedy D, Golley R, et al. The Relative Validity of the Menzies Remote Short-Item Dietary Assessment Tool (MRSDAT) in Aboriginal Australian Children Aged 6-36 Months. Nutrients 2018;10:590.

75. Rodgers K, Willis D, Thomas R. Environmental factors influencing Aboriginal nutrition in western New South Wales. Health Promot $J$ Austr 1998;8:18-23.

76. Arnhem Land Progress Aboriginal Corporation. 2015/2016 alpa annual report. Darwin NT: Arnhem Land Progress Aboriginal Corporation, 2016.

77. Hoy W, Manning R, Tungatalum L, et al. A profile of sales audits of a remote Aboriginal community's general store: 1992 and 2011. Aust $N$ Z J Public Health 2014;38:94

78. Brimblecombe J, Ferguson M, Liberato SC, et al. Optimisation modelling to assess cost of dietary improvement in remote Aboriginal Australia. PLoS One 2013;8:e83587.

79. Henryks J, Brimblecombe J. Mapping Point-of-Purchase Influencers of Food Choice in Australian Remote Indigenous Communities. Sage Open 2016;6:215824401662918.

80. Rogers A, Ferguson M, Ritchie J, et al. Strengthening food systems with remote Indigenous Australians: stakeholders' perspectives. Health Promot Int 2018:33:38-48.

81. Lee AJ, Leonard D, Moloney AA, et al. Improving Aboriginal and Torres Strait Islander nutrition and health: Economic interventions to improve access to healthy food. Med J Aust 2009;190:547-8. 
82. The Parliament of the Commonwealth of Australia. Everybody's business, remote Aboriginal and Torres Strait community stores. House of representatives Aboriginal and Torres Strait Islander affairs committee. Canberra, Australia: Commonwealth of Australia, 2009.

83. Sharma M, Catalano HP, Nahar VK, et al. Applying Multi-Theory Model (MTM) of Health Behavior Change to Predict Water Consumption Instead of Sugar-Sweetened Beverages. J Res Health Sci 2017; 17:e00370.

84. Gase LN, Robles B, Barragan NC, et al. Relationship between nutritional knowledge and the amount of sugar-sweetened beverages consumed in Los Angeles county. Health Educ Behav 2014:41:431-9.

85. Zoellner J, Estabrooks PA, Davy BM, et al. Exploring the theory of planned behavior to explain sugar-sweetened beverage consumption. J Nutr Educ Behav 2012;44:172-7.

86. Daniel M, Lekkas $\mathrm{P}$, Cargo M, et al. Environmental risk conditions and pathways to cardiometabolic diseases in Indigenous populations. Annu Rev Public Health 2011;32:327-47.

87. Popkin BM, Hawkes C. Sweetening of the global diet, particularly beverages: patterns, trends, and policy responses. Lancet Diabetes Endocrinol 2016;4:174-86. 